\title{
Determinants of Poverty among Farming Households in Nigeria
}

\author{
F.O. Ogwumike 1 \\ M.K. Akinnibosun \\ Department of Economics, University of Ibadan, \\ Ibadan, Nigeria.
}

\section{Doi:10.5901/mjss.2013.v4n2p365}

\begin{abstract}
This study investigated the determinants of poverty among farming households in Nigeria. The study adopted the National Bureau of Statistics (NBS) measure of poverty and employed the logit regression model to estimate the effect of the socio-economic variables on poverty among farming households. The results show high incidence of poverty among farming households. Age, size of household, income, and number of farms are major determinants of poverty among farming households. Further, living in the North-east, North-central, South-east, and South-south geo-political zones relative to North-west are major determinants of poverty. The results of marginal effects analysis reinforces the conclusion that the above factors are major determinants of poverty among farming households. Investing in the agricultural sector to reduce poverty should be a matter of priority. Measures aimed at improving both the quality of land and access to inputs could enhance the productivity of farmers. Though poverty is predominant in all the zones, a flexible approach to address the specific challenges of each zone rather than generalized measures could accelerate the pace of sustainable poverty reduction in the rural areas in particular and the country in general.
\end{abstract}

Keyword:Poverty, farming household, logit regression, marginal effects, farm inputs.

\section{Introduction}

Agriculture is the economic stronghold of the majority of households in Nigeria. It contributes about 45 per cent of GDP and employs nearly two-thirds of the country's total labour force. Further, it is the source of livelihood for about 90 per cent of the rural population and provides raw materials for agro-allied industries. Nigeria's huge agricultural resource base offers great potential for growth not only for the rural sector but the entire economy. However, in spite of the enormous natural resources in the country, rising poverty remains a real challenge. For example, aggregate poverty rose from 27.2 per cent in 1980 to 65.6 per cent in 1996. It declined to 54.4 per cent in 2004 and increased to about 62.6 per cent in 2010 based on preliminary estimates by the National Bureau of Statistics (NBS). The rural poverty trend closely mirrors aggregate poverty. It increased from 28.3 per cent in 1980 to 69.3 per cent in 1996, declined to 63.3 per cent in 2004 and increased to 69.0 per cent in 2010. Though, urban poverty has equally been on the increase (from 17.2 per cent in 1980 to 58.2 per cent in 1996; down to 43.2 per cent in 2004 and rose to 51.2 per cent in 2010) the incidence and severity of poverty have been more in the rural than in urban areas. For instance, after more than a decade of reforms, since the return to civilian rule in 1999, and despite the resurgence of the middle class, poverty has defied several policy measures put in place to check it. Rural poverty seems, therefore, to be a major driver of aggregate poverty in Nigeria.

Poverty has many causes, all of which reinforce one another. The sources include lack of assets, such as land, tools, credit and supportive networks of friends and family; lack of basic services, such as clean water, education and health care; and lack of employment income, to provide food, shelter, clothing and empowerment. Some of these factors directly cause poverty. Others contribute indirectly by producing inequality - by stiffling the political power of certain sectors of the population, for example or denying them their human rights (Chukwuemeka, 2008). Since the sources of poverty are diverse, it should be seen as a multi-dimensional problem that calls for a solution with a multi-pronged approach, especially as it affects farming households who face multiple disadvantages.

1 For correspondence, please contact Dr. F. O. Ogwumike at foogwumike@yahoo.com 
The foregoing implies that identifying the determinants of poverty in rural areas is very crucial to understanding not only the causes of poverty, but for formulating policies directed at its reduction. The bulk of agricultural production in Nigeria takes place in the rural areas where ironically, the level and incidence of poverty are most pronounced. Since poverty is a major constraining factor among farming households, it is important to investigate the trend, structure and determinants of poverty among farming households in Nigeria. The major research questions this study tries to answer are:

- What is the extent of the poverty status among farming households?

- What are the determinants of poverty among farming households in Nigeria?

\section{Brief Literature Review}

Rural infrastructure in Nigeria has long been neglected, while investment in health, education and water supplies has largely been skewed in favour of the urban areas. As a result, the rural population has extremely limited access to services such as schools and health centres, and about half of the population lack access to safe drinking water. Furthermore, limited education and poor health, perpetuate the poverty cycle. In addition, local farmers have little incentive to grow local foods, when cheaper, more palatable foods are imported. This forces local farmers to cut down prices, which reduces the income generated by the farmers. The consequence is decreased farm production in the following year.

Available evidence on determinants of poverty focus largely on household characteristics: age, sex, education, health, asset ownership, etc. These are assumed to represent opportunities and capabilities for a given household, or in other words to capture the human and physical capital that determines how vulnerable a typical household could be. The National Economic Council (2001) in a study on Malawi found that the age of the household, educational attainment, size of cultivable land and cropping pattern were major determinants of rural poverty. Further, households headed by older individuals in rural areas, tended to be poorer than those headed by younger ones. The coefficient for level of education of any adult in the household was consistently positive, significant and provided higher levels of welfare for the household.

Olaniyan (2000) in a study on Nigeria found that human capital endowments were significant determinants of the probability of a rural household being poor. Specifically, the education level of the head of the household was a significant influence on the probability of that household being poor. The impact of regional variables on rural poverty indicated that there were also significant geographic differences in the probability of a household falling into poverty. In a similar study on the effects of human capital and capabilities on rural poverty in Nigeria, Olaniyan and Bankole (2005) found that the educational level of the household head was statistically significant as it reduced the probability of the household being poor. Also, human capital has a decreasing effect on the probability of being poor among all rural households, whether they are engaged in farm activities or non-farm activities. In addition, households whose heads are engaged in farming activity have a higher probability of being poor.

Aigbokhan (2008) studied growth, inequality and poverty in Nigeria and examined the effects of age and education of household head, household size, and sector of residence on poverty. The results showed that welfare increases with the level of education. The coefficient is positively signed and statistically significant, thus implying that the less educated the head, the more likely that the household will be poor. Oni and Yusuf (2007) examined the determinants of expected poverty among rural households in Nigeria. The data for the study were analysed using three stage feasible generalized least squares (FGLS). The study found that farming households have lower mean per capita consumption compared with their non-farming households.

Using the 1994 Kenyan Welfare Monitoring Survey data in assessing determinants of poverty in Kenya, Alemayehu et al. (2001) used a binomial logit model and found that the likelihood of being poor is lower in urban than rural areas, and people living in households mainly engaged in agricultural activities are more likely to be poor, while male-headed households are less likely to be poor. Fofack (2002) found that poverty in Burkina Faso is a rural phenomenon contributing 94 per cent to total poverty. Using a probit model with binary outcomes over two reference periods, the study showed age dependency ratio, education level of household head, household assets and female literacy as significant determinants of rural poverty. 


\section{Materials and Methods}

\subsection{Data}

The data used in this study were collected by the National Bureau of Statistics (NBS) through its National Living Standard Survey (NLSS) of households conducted between September 2003 and August 2004. The sample design is a two-stage stratified sampling. At the first stage, clusters of 120 housing units called enumeration area (EA) were randomly selected from each state and the Federal Capital Territory (FCT, Abuja). The second stage involved random selection of 5 housing units from the selected EAs. A total of 600 households were randomly chosen in each of the states and the FCT, giving a total of 22,200 households in all. However, some households did not fully complete the questionnaires, thus only 19,158 were used out of which 14,512 rural and 4,646 urban households.

\subsection{Method}

In order to identify the determinants of poverty among farming households in Nigeria, a binary response model is specified to be estimated by logit regression technique. The logit specification is designed to analyse qualitative data reflecting a choice between two alternatives, which in this case are the poor, and the non-poor. The choice of the logit model is premised on the fact that ordinary least squares assumes a continuous dependent variable while in the case of poverty; the response is a binomial process taking the values of 1 for poor and 0 for non-poor.

Further, level regression imposes constant parameters over the entire distribution. The assumption that the poor are not fundamentally different from the rich may not be a plausible one (see Grootaert, 1997 and Bekouin, 2000]). The logit method gives parameter estimates that are asymptotically efficient, and consistent. Indeed, the logit approach is known to produce statistically sound results (Gujarati and porter, 2009).

The probability of being poor is specified as the value of the cumulative distribution function of $Z$ which is specified as a function of the explanatory variables. The equation is of the form:

$$
\operatorname{Prob}(\operatorname{Poor}=1)=F(Z)=e^{z}\left(1+e^{z}\right)=F\left(\beta_{0}+\beta_{1} X\right)
$$

Where:

$F(Z)=e^{z l}\left(1+e^{z}\right)$ is the cumulative logistic distribution, representing the probability of being poor. $Z$ is the poverty line; $\beta$ is the vector of parameters, and $x$ the vector of explanatory variables, these include personal characteristics of the household, household characteristics, physical capital and community factors. The personal characteristics include age, educational level of father, sex of the household. Household characteristics include household size, marital status of head of household? Physical capital includes number of farm and land holdings and income from farming activities, while community factors include location of residence i.e., rural or urban and geopolitical zone of household.

For non poor

$$
\text { Prob }(\text { Non poor }=0)=1-F(Z)=e^{z l}\left(1+e^{-z}\right)
$$

Therefore, equation 1 and 2 can be written as:

$$
\frac{F(Z)}{1-F(Z)}=\frac{1+e z i}{1+e-z i}
$$

Equation 3 is simply the odd ratio in favour of household falling below the poverty. This is the ratio of the probability that a household will be poor to the probability that it will not be poor. The natural log of equation 3 results into:

$$
\mathrm{L}_{\mathrm{i}}=\mathrm{Ln}\left(\frac{\mathrm{F}(\mathrm{Z})}{1-(F)}\right)=\mathrm{Z}_{\mathrm{i}}=(0+(1 X 1 \ldots \ldots(k X k-)
$$

Equation 4 will be used for the estimation of the logit model in this study. Therefore, the model of determinants of poverty among farming households is based on the following empirical logit specification. 
$\mathrm{Li}=\operatorname{Ln}\left((F(Z)) /(1-F(Z))=\beta_{0}+\beta_{1}\right.$ Agehh $+\beta_{2}$ hhsize $+\beta_{3}$ finc $+\beta_{4}$ fcnt

$+\beta_{5}$ sex $+\beta_{6}$ landown $+\beta_{7}$ nsecto $+\beta_{8}$ Fedu $+\beta_{9} N E+\beta_{10} N C+\beta_{11} S W$

$+\beta_{12} \mathrm{SE}+\beta_{13} \mathrm{SS}+\beta_{14 \text { Mono }}+\beta_{15}$ Poly $+\beta_{16} \operatorname{lnfu}+\beta_{17}$ Div $+\mathrm{e}_{\mathrm{i}----\beta_{-}--}[5]$

Where

$L_{i}$ is the logit (i.e, natural logarithm of the odd ratio),

$F(Z)=1$ if household is poor and $1-F(Z)=0$ if household is not poor as the dependent variable (poverty status of household).

$$
\left(\frac{\mathbf{F}(\mathbf{Z})}{\mathbf{1 - ( F )}}\right) \text { = the odd ratio in favour of the probability of being poor or not poor, }
$$

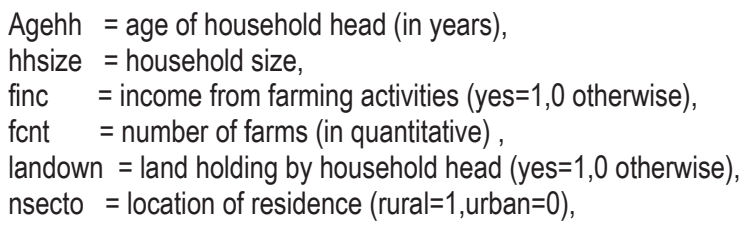

Other variables are categorical and dummy is generated for them as follows: marital status (monogamous $=1,0$ otherwise) never married used as base category. Zone (south west=1,0 otherwise) Northwest is used as base category; Fedu is father's education level (formal $=1$, otherwise $=0$ ) where informal is used as base category, and ei is the random error term.

In economics a prior criterion refers to the sign, size of the parameter and the economic relationship between the variables. A prior expectation of this logit regression model is that: $\beta_{0}, \beta_{1}, \beta_{2}, \beta_{16}>0, \beta_{3}, \beta_{4}, \beta_{6}, \beta_{8}, \beta_{14}<0$, and, $\beta_{5}, \beta_{7}, \beta_{8}, \beta_{9}, \beta_{10}, \beta_{11}, \beta_{12}, \beta_{13}, \beta_{15}, \beta_{17}<$ or $>0$.

Since the logit model is not linear, the marginal effects of each independent variable on the dependent variable are not constant but are dependent on the values of the independent variable Greene (1993). Thus, as opposed to the linear regression case, it is not possible to interpret the estimated parameters as the effect of the independent variables upon poverty.

Therefore, the analysis will be based on the marginal effect of each variable on the probability of the effect. This is because logit coefficients do not represent the standard marginal effects represented by linear regression coefficients. However, the marginal effects combine the predicted probability of being poor with the estimated logit coefficients.

The marginal effect is derived by taking the partial derivative of equation (1) with respect to an independent variable as follows:

$$
\frac{\partial F(Z)}{\partial X_{i}}=\frac{\left(i e^{-z}\right.}{\left[1+e^{-z}\right]^{2}} \quad \text { where } z=\beta_{0}+\beta_{1} X_{1}+\beta_{2} X_{2}+\ldots \ldots+\beta_{k} X_{k}
$$

Where $\beta_{i}$ is a vector of parameters that associates with the explanatory variable $x_{i}$.

The parameters of the logit model are then estimated using the maximum likelihood estimation method. The assumption is that the response variable has a sample of $\mathrm{N}$ observations, which are independent.

This study adopted the Foster, Greer and Thorbecke (1984) approach to estimate the incidence, depth and severity of poverty in the study area. The FGT indices are calculated by taking the proportional shortfall in expenditure for each poor household and normalizing the sum by the population size. These three measures are all based on a single formula, but each index puts different weights on the degree to which a household or individual falls below the poverty line. This method is employed to determine the extent and level of poverty among farming households while the logit (binomial) regression model is used to estimate the effect of selected variables (determinants) on the poverty status of farming households in Nigeria. The maximum likelihood technique is used for estimation. The poverty line as calculated by the National Bureau of statistics (NBS) was adopted in this study. This is based on the two-third of mean per capita expenditure of the sampled households. 


\section{Results and Discussion}

Table 1 shows extent and pattern of poverty among farming households. Poverty incidence among all farming households was about 47 per cent, rural 52 per cent and urban 33 per cent. Female-headed households had less poverty than their male-headed counterpart. Northern geo-political zones have higher incidence of poverty than their southern counterparts. Poverty depth or gap and severity were higher in rural than urban households, among male-headed households than female-headed households, and among the northern than the southern geo-political zones. The higher incidence of poverty among male-headed households may be partly due to the small number of female-headed households in the total sample. It could also be as a result of the fact that in most parts of rural Nigeria, female-headed households are always involved in many other occupations besides farming, especially trading (Omonona, 2009).

Table 1: Poverty Profile of Farming Households (2004)

\begin{tabular}{lccc}
\hline & $\begin{array}{c}\text { Incidence } \\
\text { P0 }\end{array}$ & $\begin{array}{c}\text { Depth } \\
\text { P1 }\end{array}$ & $\begin{array}{c}\text { Severity } \\
\text { P2 }\end{array}$ \\
\hline National Sector & 0.472 & 0.192 & 0.104 \\
Rural & 0.518 & 0.213 & 0.115 \\
Urban & 0.327 & 0.127 & 0.068 \\
Sex & & & \\
Male & 0.505 & 0.206 & 0.111 \\
Female & 0.279 & 0.108 & 0.058 \\
Zone & & & \\
North west & 0.700 & 0.294 & 0.158 \\
North east & 0.636 & 0.265 & 0.140 \\
North central & 0.605 & 0.282 & 0.168 \\
South west & 0.286 & 0.102 & 0.052 \\
South east & 0.218 & 0.065 & 0.029 \\
South south & 0.259 & 0.082 & 0.037 \\
\hline
\end{tabular}

Source: Author's computation from NLSS (2004) data.

The result of the logit regression of the determinants of poverty among farming households is presented in Table 2 . The $X^{2}$ statistics test the null hypothesis of all estimated coefficients taken together being equal to zero. The value of the $\mathrm{X}^{2}$ statistics for the model is 3431.08 and is significant at 1 per cent confidence level. The value of the coefficient of determination is low for most empirical studies using cross sectional data,. In this case, the pseudo - $R^{2}$ is 0.2409 , that is, 24.09 per cent of the poverty status of the households is explained by the selected explanatory variables. The value of this pseudo $-R^{2}$ suggests a reasonable efficiency of the model.

Table 2: Determinants of Poverty among Farming Households

\begin{tabular}{lcccc}
\hline Variable & Estimated coff. & Standard error & Z-statistics & $P[\mathrm{Z} />\mathrm{Z}]$ \\
\hline Constant & -1.6320 & 0.2521 & -6.47 & $0.000^{\text {***}}$ \\
Agehh & -0.0068 & 0.00182 & -3.71 & $0.000^{\text {*** }}$ \\
Hhsize & 0.3517 & 0.0126 & 27.89 & $0.000^{* * *}$ \\
Finc & $-4.51 \mathrm{e}-06$ & $4.49 \mathrm{e}-07$ & -9.22 & $0.000^{* * *}$ \\
Fcnt & -0.0086 & 0.0209 & -4.15 & $0.000^{\text {*** }}$ \\
Sex & -0.0086 & 0.1119 & -0.08 & 0.939 \\
Landown & -0.0384 & 0.0680 & -0.57 & 0.572 \\
\hline
\end{tabular}




\begin{tabular}{|c|c|c|c|c|}
\hline Secto & 0.5575 & 0.1057 & 5.28 & $0.000^{* * *}$ \\
\hline Fedu & -0.0760 & 0.0607 & -1.25 & 0.211 \\
\hline North west & - & - & - & - \\
\hline North east_z & -0.2035 & 0.0757 & -2.69 & $0.007^{* * *}$ \\
\hline North centr_z & -0.8878 & 0.0820 & -10.83 & $0.000^{* * *}$ \\
\hline South west_z & -1.4308 & 0.1027 & -13.83 & $0.000^{* * *}$ \\
\hline South east_z & -2.1520 & 0.0896 & -24.01 & $0.000^{* * *}$ \\
\hline South south_z & -1.5909 & 0.0914 & -17.41 & $0.000^{* * *}$ \\
\hline Never married & - & - & - & - \\
\hline mono_marr & 1.4394 & 0.1838 & 7.83 & $0.000^{* * *}$ \\
\hline poly_marr & 1.3695 & 0.1982 & 6.91 & $0.000^{* * *}$ \\
\hline informal_un & 1.1905 & 0.6484 & 1.84 & $0.066^{*}$ \\
\hline div/wid/sepr_ & 1.1351 & 0.2045 & 5.55 & $0.000^{* * *}$ \\
\hline $\begin{array}{l}\text { LR chi2 }(17)=3431.08 \\
\text { Pro }>\text { chi2 }=0.0000\end{array}$ & & $\begin{array}{c}\text { Pseudo=R2=0.2409 } \\
\text { Log likelihood = - } \\
5407.15\end{array}$ & & \\
\hline
\end{tabular}

Note: ${ }^{* * *},{ }^{* *}$, and ${ }^{*}$ denote statistical significance at $1,5,10$ per cent levels, respectively.

Source:Author's computation from NLSS (2004) data.

The estimated $\beta$ coefficients (intercepts included) of fifteen of the estimated variables are statistically significant at 10 per cent. The variables include age of the household head (Agehh), household size (Hhsize), income from farming (Finc), number of farms (Fcnt), location of residence of household head (Secto), geo-political zones of household and marital status.

Age of the household head (Agehh) was inversely related to poverty status and statistically significant at 1 per cent level of significance. This is due to the fact that at the early stage of life there is always greater energy which would probably have helped the households at that time to increase output and income. However, as the household head gets older, the energy begins to depreciate and output and income also decline which increases the chances of the household falling into poverty. This supports the findings of Ahmed et al. (2008), that age of the household head is very important for reducing the poverty status of the household.

Household size (Hhsize) was a significant determinant of poverty among farming households. There are two opposing interpretations for the relationship between household size and poverty status. The larger the household, the greater will be the total consumption needs and thus, the higher the poverty status of the household. However, to the extent that a larger household size also augments the total labour supply of the farming household thereby enhancing its income-generating potential, the effect of a larger household size on poverty status may be neutralized. This study shows that household size is positively related to poverty status and is significant at 1 per cent. This implies that as the household size increases, the poverty status of the household also increases. This result is consistent with the findings of Lipton (1983), Schubert (1994), Olaniyan (2005), Etim (2007), Etim and Edet (2007a \& b) and Etim et al., 2008) who concluded that the size of the household is positively related to the poverty status of the household.

Income from farming activities (Ficn) is inversely related to the poverty status of the household and significant at 1 per cent. This shows that as the income from farming activities increases, the probability of being poor decreases. This reveals that the likelihood of a farming households being poor is reduced if the income from farming activities increases. This finding is supported by Akinleye (2004). The number of farms owned by households (Fcnt) is also a very important determinant of poverty. In this study, the number of farms owned by the household is inversely related to the poverty status of the household and significant at 1 per cent. This shows that as the number of farms owned by the household increases, the probability of being poor decreases. This is a form of physical asset that farming households have, which will improve their standard of living. This result is confirmed in the study by Olaniyan (2005) that showed that house ownership helps to reduce the poverty status among farming households.

Sector/location (Secto), which could either be rural or urban, has a positive relationship with the poverty status of the household and is significant at 1 per cent. Based on the literature, the incidence of poverty is higher in the rural areas 
where farming is the core occupation. This study shows that rural households have a higher probability of being in poor. This is may be due to the availability of diverse jobs in the urban areas, some of which are well paid relative to the jobs in the rural areas. Also, the lack of infrastructural facilities like good roads, electricity, and access to markets limits incomeearning opportunities in the rural areas.

The level of education of the head of the household (Fedu) was not significant, though it had the expected sign of being inversely related to the probability of the household being poor. The result is consistent with the findings by Olaniyan (2005).

The coefficients for the geo-political zones were significant at one per cent and have an inverse relationship with the poverty status of the household. Households living in the northeast, north central, south west, south east and southsouth relative to the north west have less probability of being poor. The impact of regional variables on rural poverty indicates that there are significant regional differences in the probability of falling into poverty, as all the coefficients are significant. Nigeria is a big country with different geographical, social and cultural settings/variations? All these combine to produce differences in the probability of being poor in these regions. This result also agrees with that of Olaniyan (2005) that geopolitical zone has a negative impact on the probability of being poor.

Marital status in this study was categorized into four - monogamous married, polygamous married, informal union and divorced, widowed or separated. The results show that the status of monogamous married, polygamous married, informal union and divorced, widowed or separated relative to never married has a positive effect on the probability of being poor and all were significant at one per cent expect for monogamous married that was significant at 10 per cent.

The marginal effects of the determinants of poverty can be used to assess the impact of explanatory variables. Table 3 presents the results of the marginal effects of explanatory variables on the poverty status of the households.

Table 3: Marginal Effects of Binomial Logit Model

\begin{tabular}{|c|c|c|c|c|}
\hline Variable & $\mathrm{dy} / \mathrm{dx}$ & Standard error & z-statistics & $\mathrm{P}[\mathrm{Z} />\mathrm{Z}]$ \\
\hline Agehh & -0.0016 & 0.0004 & -3.71 & $0.000^{\star \star \star}$ \\
\hline Hhsize & 0.0824 & 0.0029 & 28.67 & $0.000^{\star \star *}$ \\
\hline Finc & $-1.06 \mathrm{e}-06$ & 0.0000 & -9.22 & $0.000^{* * *}$ \\
\hline Fent & -0.0230 & 0.0049 & -4.15 & $0.000^{* * *}$ \\
\hline Sex & -0.0020 & 0.0262 & -0.08 & 0.939 \\
\hline Landown & -0.0090 & 0.0158 & -0.57 & 0.571 \\
\hline Secto & 0.1361 & 0.0263 & 5.17 & $0.000^{* * *}$ \\
\hline Fedu & -0.0179 & 0.0014 & -1.25 & 0.213 \\
\hline North west_z & - & - & - & - \\
\hline North east_z & -0.0483 & 0.0181 & -2.66 & $0.008^{* * *}$ \\
\hline North centr_z & -0.2162 & 0.0199 & -10.87 & $0.000^{* * *}$ \\
\hline South west_z & -0.3405 & 0.0222 & -15.36 & $0.000^{* * *}$ \\
\hline south east_z & -0.4970 & 0.0158 & -30.84 & $0.000^{* * *}$ \\
\hline South south_z & -0.3771 & 0.0190 & -19.86 & $0.000^{* * *}$ \\
\hline Never married & - & - & - & - \\
\hline mono_marr & 0.3387 & 0.0413 & 8.19 & $0.000^{* * *}$ \\
\hline poly_marr & 0.2709 & 0.0315 & 8.61 & $0.000^{\star \star \star *}$ \\
\hline informal_un & 0.2206 & 0.0847 & 2.60 & $0.009^{\star \star \star *}$ \\
\hline div/wid/sepr_ & 0.2276 & 0.0334 & 6.81 & $0.000^{\star * *}$ \\
\hline
\end{tabular}

Source: Binomial logit model output.

Notes: ${ }^{* * *}$ significant at 1 per cent level; ${ }^{* *}$ significant at 5 per cent level; ${ }^{*}$ significant at 10 per cent level. 
The results show that the marginal effect of age of the household head (Agehh) is significant at one per cent level of significance; and that an increase of one per cent of the age of the household head increases the probability of the household being poor by about 0.2 per cent. The result is consistent with that of the Khalid et al (2005) but does not support the findings of Baulch and McCulloch (1998) who found no significant effect on the probability of the household being poor due to change in the age of the household head.

Household size (Hhsize) is significant at 1 per cent level and a 1 per cent increase in Hhsize will increase the probability of that household being poor by 8.24 per cent. This result is consistent with that obtained by Okurut (2002). This is because a larger household will likely have more children, who are unproductive but take a big proportion of the household income in terms of school requirements, medical attention, food and clothing.

The marginal effect of income from farming activities (Finc) is significant and a one per cent increase in income will reduce the probability of a household being poor by 16.0 per cent.

The sector of residence (Secto) is a major determinant of poverty among faming households as the marginal effect of an increase in the chances of residing in the rural area increases the probability of a household being poor by about 14.0 per cent.

The marginal effects of geo-political zones are significant at one per cent and imply that a 1 per cent change of residence from North west to North east, North central, South west, South east and South south will reduce a household's probability of being poor by 4.8 per cent, 21.6 per cent, 34.1 per cent, 49.7 per cent and 37.7 per cent respectively.

With respect to marital status, the marginal effects of a one per cent change in a household's marital status from monogamous, polygamous, informal union, and divorced/widow/separated to never married increases the probability of a household being poor by 33.8 per cent, 27.1 per cent, 22.1 per cent, 22.8 per cent respectively. Thus marriage and the benefits it accrues has a positive effect in reducing poverty among farming households relative to never married heads of farming households.

\section{Conclusion}

This study examined the determinants of poverty among farming households in Nigeria. The determinants of poverty include socioeconomic characteristics of the household, physical assets and community factors which include location of residence and geopolitical zone. The major findings of the study include: the farmer's income is inversely related to the poverty status of the household; and that a one per cent increase in income from farming activities will reduce the probability of a farming household being poor by 16 per cent.

The differential impacts of the marginal effects of the geo-political zones on the probability of reducing poverty among farming households show that policies should take the peculiar features of the zones into consideration in advancing measures to reduce poverty.

Measures to reduce poverty among farming households in Nigeria should be aimed at improving the fertility of the land and output. The provision of basic infrastructure in the rural areas in particular is a necessary requirement for poverty alleviation. Also, access to credit facilities by farmers could be enhanced through cooperative societies in the rural areas. All these will improve the income of farming households and consequently their standard of living and thus reduce poverty.

\section{References}

Alemayehu, G et al (2001) Determinants of poverty in Kenya: Household-level analysis. Kenya Institute for Public Policy Research and Analysis (KIPPRA). KIPPRA Discussion Paper No. 9

Aigbokhan, B (2008) Poverty, growth and inequality in Nigeria: A case study. African Economic Research Consortium (AERC). Nairobi, Kenya.

Akinyele (2004) Characteristics and determinants of poverty among fish farmers in Lagos State.

Apata, T. G. et al (2010) Determinants of rural poverty in Nigeria: Evidence from small holder farmers in South-Western, Nigeria. Journal of Science and Technology Education Research Vol. 1(4), pp. 85-91

Baulch, B. and McCulloch, N. (1998) Being poor and becoming poor: Poverty status and poverty transitions in the rural Pakistan. Working Paper No. 79, Institute of Development Studies, University of Sussex.

Bekouin, K (2002) Analysis of poverty in rural area in Sub-Saharan Africa: Case of Cote d'Ivoire. African Journal of Economic Policy, Vol. 9 No. $155-76$ 
Chukwuemeka, E (2008). The substance of public administration in Nigeria: A compendium of public policy and local government, Enugu: Computer Edge

Etim and Edet (2007) Determinants of rural poverty among broiler farmers in Akwa Ibom State. In: Agwunobi and Olawoyin (Eds.), Proc. the 32nd Annual Conference of the Nigerian Society for Animal Production Held at the University of Calabar

FAO (2000) Inter-agency experiences and lessons: From the forum on operationalising sustainable livelihoods approaches. Pontignano (Siena) 7-11 March 2000. FAO, Rome.

Fields, G.S. (2000) The dynamics of poverty, inequality and economic well-being: African economic growth in comparative perspective. Journal of African Economies, Vol. 9 (suppl. 1), Pp. 45-78.

Fofack, H (2002) The nature and dynamics of poverty determinants in Burkina Faso in the 1990s. World Bank Working Paper, May, 2002.

Greene, H.W (2000) Econometric analysis. Fourth edition. Printice-Hall, Englewood, Cliffs, NJ, USA.

Grootaert, C. (1997) The determinants of poverty in Cote d'Ivoire in the 1980s. Journal of African Economies (2) 169-96.Growth versus other Strategies": in NES op cit.

Gujarati and Porter (2009) Basic econometric, $5^{\text {th }}$ edition. New York: McGraw-Hill.

International Fund for Agriculture Development (IFAD), (2009) Enabling poor rural people to overcome poverty. http://www.ifad.org/poverty/index.htm Income and widespread Rural Poverty, paper presented at the second 1987 NISER Seminar series.

Khalid, U., Shahnaz, L. and Bibi, H. (2005) Determinants of poverty in Pakistan: A multinomial logit approach. The Lahore Journal of Economics, 10(1), 65-81.

Khan, M (2001) Rural poverty in Developing Countries: Implications for public policy. P.1 London: OPM.

National Planning Commission (2004) Meeting everyone's NEEDS: National Economic Empowerment Strategy NEEDS. Abuja.

Olaniyan, O. (2000) The role of household endowments in determining poverty in Nigeria. University of Ibadan, Nigeria

Olaniyan O. and Bankole, A. S. (2005) Human capital, capabilities and poverty in rural Nigeria. Research Report submitted to the African Economic Research Consortium

Okunmadewa, F. Y. (2002). Social capital and poverty reduction in Nigeria. Revised Report Submitted to Africa Economic Research Consortium (AERC), Nairobi, Kenya, for the Second Phase Collaborative Poverty Research Project.

Okurut, F.N. (2002) The impact of foreign aids flows on private sector investment in Uganda, 1984-94. A final report submitted to AERC.

Omonona, B. T. (2009) Knowledge review on poverty and rural development in Nigeria. Strategy Support Program (NSSP) Background Paper. Washington,

Omonona, B. T. (2008) Quantitative analysis of rural poverty in Nigeria. International Food Policy Research Institute: Brief No. 17

Oni and Yusuf (2007) Determinants of expected poverty among rural households in Nigeria. Paper presented at the Centre for the Study of African Economics

Oyeranti and Kolawole (2005) Policies and programmes for poverty reduction in rural Nigeria. An Interim Research Report Submitted to the African Economic Research Consortium (AERC), Nairobi for the Second Phase Collaborative Poverty Research Project.

Pinstrup and Pandya (2001) Agricultural growth is the key to poverty alleviation in low-income developing countries. The Unfinished Agenda.

Schubert, R. (1994). Poverty in developing countries: Its definition, extent and implications. Journal of African Economies, Pg: $17-40$

Udoh, E (2000) Land management and resource-use efficiency among farmers in South-west.

World Bank (1996). Nigeria-Poverty in the midst of plenty. The challenges of growth with inclusion. Report No. 14733 UNI. Washington, D.C. (May)x 
